\title{
How to Fix Coordination Lags in the Keynesian Macroeconomical Intervention?
}

\author{
Tommi P. Laiho \\ Correspondence: Tommi P. Laiho, Rymättylänkatu 19 B 6, 20740, Turku, Finland. \\ Received: August 24, 2020 Accepted: September 23, 2020 Online Published: September 29, 2020 \\ doi:10.11114/bms.v6i3.5030ＵRL: https://doi.org/10.11114/bms.v6i3.5030
}

\begin{abstract}
The Keynesian macroecomic intervention often fails. This is most likely due to forecasting problems of the macroeconomy. This article present a software idea of fuzzy logic controlling unit which replaces long and tedious human intervention in macroeconomic stimulation process. The Keynesian Macroeconomic intervention now made by officials and politicians is suggested to be made by much faster and more purposeful automatic computer adjustment process. It is assumed that this kind of just in time and very fast automatic computer intervention would lead to optimimal usage of the resources in a much better way than any current human lead systems would be able to do.
\end{abstract}

Keywords: business cycles, artificial intelligence, macroeconomic stimulation, Keynes, fuzzy logic

\section{Introduction}

Currently, macroeconomic stimulation judgement is based on long and tedious political processes. Therefore the timing of fiscal stimulation is misaligned with economic recession; it usually arrives late or even after the economy has already started to recover from recession. (Blinder 2004)

Fiscal politics often fail because it is almost an impossible to forecast future business cycles. However, we propose a solution to present fiscal polities "just in time" using controlled macroeconomic stimulation processes based on a fuzzy controlling theory on an extensive supercomputer network. The premise of this is not to make decisions to forecast the future under uncertain circumstances, but to present macroeconomic guidance based on a adaptive real-time fuzzy control logic.

Long time ago, Slutzky noticed that the components of aggregate demand follow a random walk manner. He stated that Russian states lottery numbers behaved in a similar manner as the time trends of economic growth. In his time, this was a huge step towards understanding the random walk manner of economic growth processes. Since then, minor improvements have been made to forecasting methods and new statistical innovations that take account a random component within the economic growth process like in DSGE statistical forecasting methods have arisen. However, there is limited guaranteed information about the future of annual fluctuations in economic growth. Furthermore, this is precisely the problem with Keynesian methods in stimulating economic growth in the event the economy goes into recession. How then can we properly guide macroeconomics if we do not know that where the economy truly is heading before-hand? (Drautzburg 2019)

A potential solution to this problem and to prosperiously guide the economy is by not forecasting its' movements at all. Following this, it may be feasible to vary how the economy could adapt its behaviour to face new and unpredictible situations. Using of a huge central computer with a complex software based on fuzzy controller theory, we could make adaptions to the economy in a time-frame of fractions of a second (as opposed to many weeks or months during which there is is a time lag in current Keynesian macroeconomic stimulation processes). Therefore, Keynesian macroeconomic guidance should be left to computers alone to the exclusion of any human intervention.

The current industrial economy is a complex union of a huge amout of data with has billions of parametres and variables. The internet was invented by physicists to handle massive data generated by particle accelerators. However, existing computers are still being developed to the capacity to control this type of big data. For example, digital money could be followed as it moves from consumers to consumer services, and investments in the industrial sector could be also followed in real-time with the help of the internet and supercomputers. Furthermore, governmental investments and monetary transactions could be traced as they occur as well as import and export figures managed by custom services (Cern 2020). 
This type of system should be combined with an advanced AI unit that could be programmed with the help of the fuzzy logic controlling methods. Furthermore, we need a stimulation fund, which would prompt sudden movements in the AI. For this, we used a fund of approximatley USD 80 billion to be used as soon as needed without undue delays. During an on-going recession, the fund can be used directly and when the economy overheats there is the possibility of raising the total amount of the stimulation fund through taxation. This tax will in turn be returned to tax payers during difficult finanical times in the form of governmental AI stimulation.

The image below illustrates a simplified view of how information moves in our modern industrial economy. All arrows point to the direction of moving data. Two-sided arrows indicate communication and real-time guidance between the central computer and financial markets. Single-sided arrows indicate a channel where markets only send the information to the central computer but do not get any feedback. These fields will get their feedback later in a form of stimulation fund usage policy and general interest rate defined by the AI and its central computer. For example in our model, Keynesian stimulation will affects the public sector services through real-time stimulation policies, interest rates will affect consumer markets and banking loan decisions will be wiser because they are all under the control of the AI and its central supercomputer. The difference is between the current Keynesian model and human intervention in exisitng markets is that the current one has a minmila time lag to effect the markets is minimal while existing ones based on human interventions require many weeks or even months (Blinder 2004).

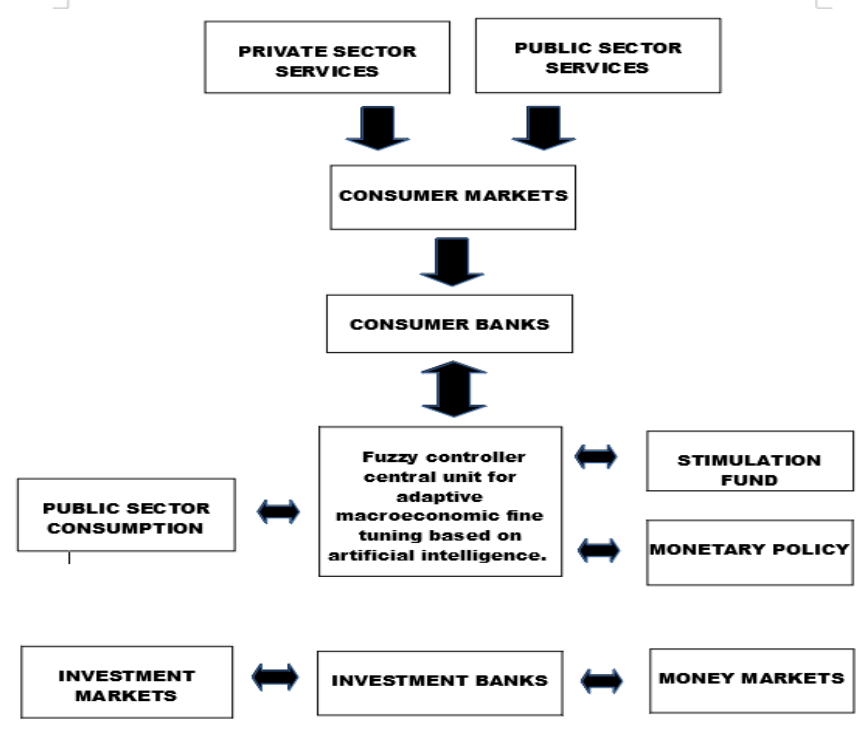

Figure 1. Information Flow of the Economy

Both systems target the same goal: They all aspire for more steady growth of the economy a shorter recession period. Our proposed model will probably not remove all the effects of the business cycle but will slightly balance the situation. This simply means that overheated seasons of the business cycle and recession sessions will be now shorter and people will be able to handle them better. Although black swan-like effects of the COVID-19 virus cannot be avoided completely, their effects will be diluted better by real-timed fiscal and monetary policies.

\section{Fuzzy Rules of the Mighty AI Fuzzy Logic Controller Unit}

The following example explains how the would fuzzy controller work in practice. The fuzzy controller unit follows and fine-tunes the following parts of the aggragate demand $\mathrm{C}+\mathrm{I}+\mathrm{G}=\mathrm{AD}$ and also a part of the consumption as a stimulation fund. The import and export part of the typical Keynesian demand function has been left out to simplify the model. The rules of the fuzzy controller are shown below.

The fuzzy controller's parametres are:

1. Stone Age which implies zero-level demand and an unusual shock to the society's demand.

2. Recession which implies a low society demand

3. Normal which implies a typical growth rate without a truly high demand

4. Good which implies a phase of the business cycle in which the demand is clearly beyond the normal rate

5. Exellent demand which implies a phase of the business cycle in which society's demand is ultra high and economy is overheating. 
All these rules affects the Aggregate demand, which in turn may obtain the following fuzzy values:

1. Poor which akin to a situation after a nuclear attack. The Aggregate demand is at or near zero level consumption.

2. Low which implies a serious recession in the aggregate demand.

3. Normal demand which matches the mid-phase of a typical business cycle.

4. High demand which impliesn such a level of demand that exceeds the normal phase.

5. Exellent level of demand that implies means such a phase in a business cycle in which economy is clearly overheating.

The program then makes the following analysis of the fuzzy controlling units rules and overall behavior that is under the controlling process:

Here, we can see that there is an optimal area for every part of the demand which is represented by $\mathrm{AD}=$ $\mathrm{C}+\mathrm{I}+\mathrm{G}+$ Stimulation fund. The numbers represent billions of dollars. Furthermore, on this image that there is an optimal area for all these demand items. Too much from the stimulation fund will only lead to an overheated economy.

However, if that happens, the need for a stimulation fund policy intervention will automatically drop. The subsequent image represents the fuzzy logic rules of the central computer. With all the rules at their basic middle settings, the economy is in perfect balance. However if there is a shock to the economy like sudden drop in the private consumption, the system will automatically increase demand with a stimulation fund to compensate the sudden loss.

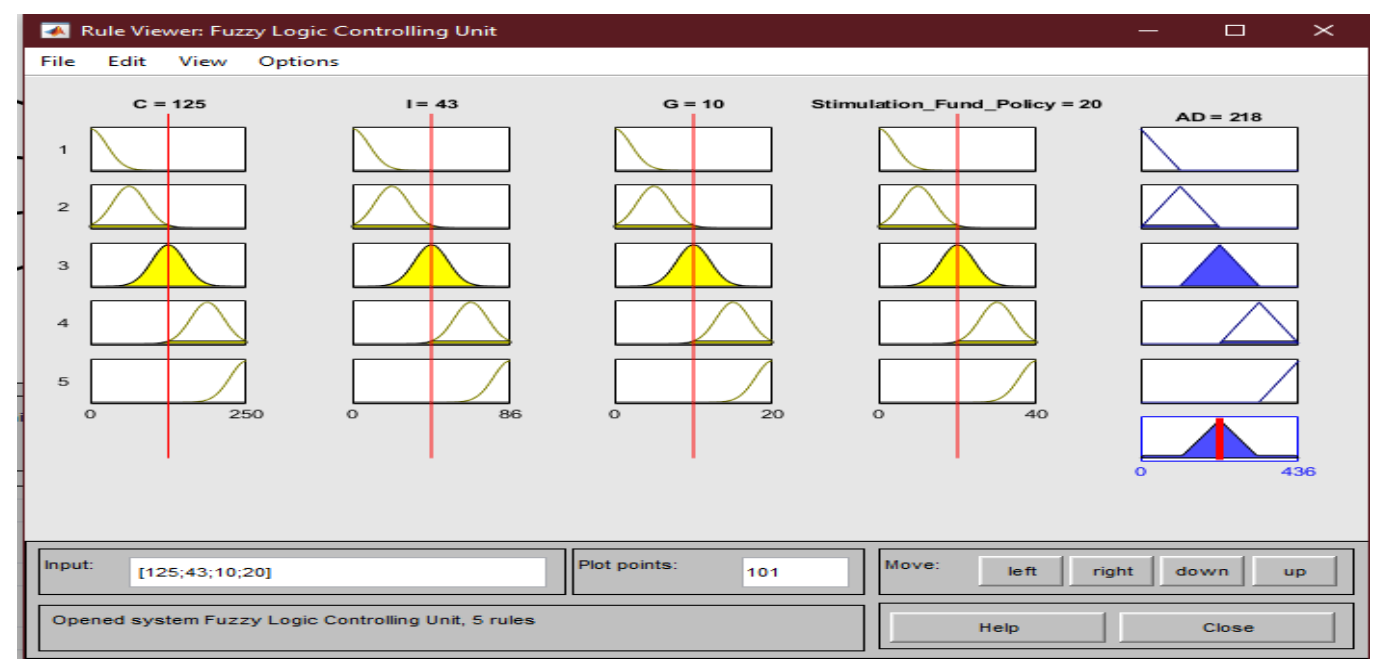

Figure 2. Fuzzy Rules of the Economy

If the $\mathrm{C}$ which is 125 billion will drop by 5 billion dollars, a stimulation fund policy will need to be increased by 5 billion dollars. The image will then appear as shown below:

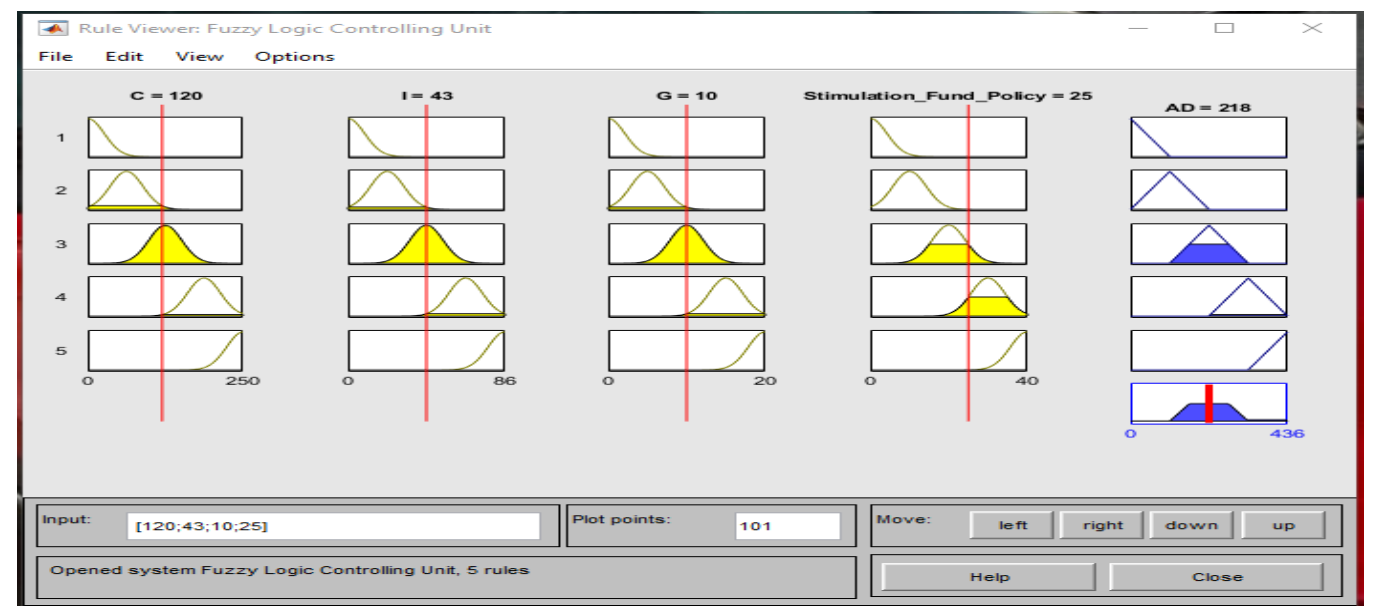

Figure 3. Adjusting process of the fuzzy logic controlling unit 
Although C is now USD 120 billion, it has been increased by the stimulation fund policy which has a USD 25 budget. The economy stays in balance and the aggrate demand is restored to USD 218 billion. The result is exactly as envisaged: A stable economy in the shortest time possible without human intervention.

\section{The Fuzzy Rules of the Business Cycle Stimulation Fund}

The fuzzy logic rules of how the business cycle stimulation fund itself work are as follows:

1. If unemployment increases, then funds for education and unemployment benefits ought to be added

2. If industrial investment decreases, then interest rates should be lowered interest rate and funds for corporate benefits added.

3. If consumer's demand decreases, then interest rates should be lowered interest rate and funds for stimulation fund policy increased.

4. If pollution increases, funds for climate change research should be increased.

5. If society income levels become too large, funds for social justice ought to be added.

6. If society's national security is under threat, funds for law and order ought to be added.

The following image shows all the fuzziness as rules of the central supercomputer:

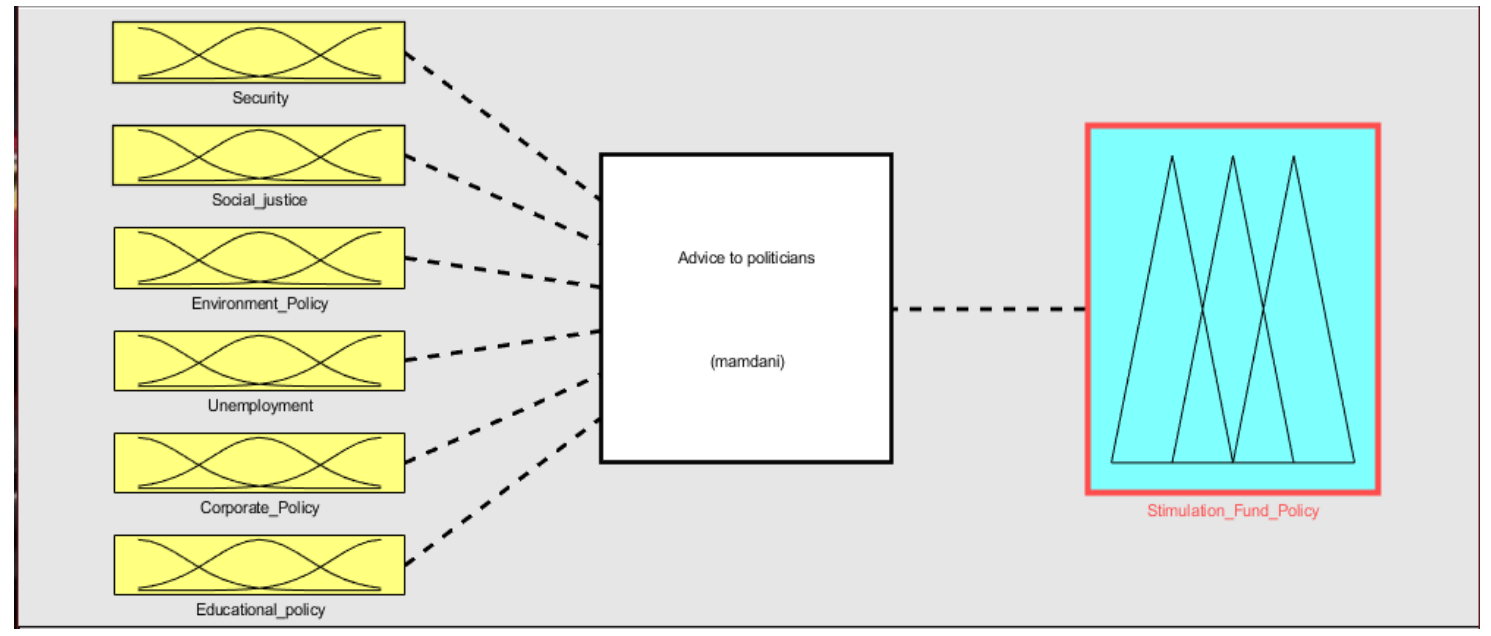

Figure 4. Fuzzy rules of the AI unit

\section{Conclusions}

The difference between human intervention and AI intervention is that AI can make decisions in nanoseconds while human beings need many weeks or even months before making such decisions. With the fuzzy logic controller unit, this planet's resources could be used in a more balanced and effective manner. This system does not contradict Keynesian stimulation policy but identifies an alternative interpretation if how this type of policy could be used effectively. This is because the problems presented by the Keynesian stimulation policy are obvious: the help that they avail comes too late, is waste of resources and may potentially cause more problems than it solves.

\section{References}

Blinder, A. S. (2004). The Case Against Discretionary Fiscal Policy by Princeton University CEPS Working Paper No. 100 June 2004 Prepared for Federal Reserve Bank of Boston conference, The Macroeconomics of Fiscal Policy, Chatham, Mass., June 14-16, 2004.

CERN. (2020).

https://home.cern/science/computing/birth-

web\#: :text=Tim\%20Berners\%2DLee $\% 2 \mathrm{C} \% 20 \mathrm{a} \% 20 \mathrm{British}$, and $\% 20$ institutes $\% 20$ around $\% 20$ the $\% 20$ world. CERN, Esplanade des Particules 1, P.O. Box, 1211 Geneva 23, Switzerland.

Drautzburg, T. (2019). Why Are Recessions So Hard to Predict? Random Shocks and Business Cycles Federal Reserve Bank of Philadelphia Economic Insights, 2019, 1st quarter 2019 Q1. 


\section{Copyrights}

Copyright for this article is retained by the author(s), with first publication rights granted to the journal.

This is an open-access article distributed under the terms and conditions of the Creative Commons Attribution license which permits unrestricted use, distribution, and reproduction in any medium, provided the original work is properly cited. 